\title{
Larvicidal and ovicidal activities, characterization and stability of Anacardium occidentale (Cashew) shell wastes
}

\author{
Rosalinda C Torres ${ }^{1,2 *}$, Alicia G Garbo ${ }^{1}$ and Rikkamae Zinca Marie L Walde ${ }^{2}$ \\ ${ }^{1}$ Industrial Technology Development Institute, Metro Manila, Philippines \\ ${ }^{2}$ Department of Science and Technology, National Research Council of the Philippines, Metro Manila, Philippines
}

\begin{abstract}
Dengue and zika continue to be the most rapidly emerging febrile diseases and pose a negative impact on social and economic activity of the country. Despite of recent innovation in dengue vaccine, eradication of the vector, Aedes aegypti, is still the best way to inhibit dengue and zika outbreaks. In this study, we evaluated the larvicidal and ovicidal activities and characterized the shell wastes of Anacardium occidentale including its stability for a period of two (2) years. The shell wastes were extracted using $95 \% \mathrm{EtOH}$ and $\mathrm{n}$-hexane and were bio-assayed for larvicidal and ovicidal activities against $A$. aegypti following the WHO standard bioassay method. The mortality was observed 24 and 48 hours after treatment and data were subjected to probit analysis to determine lethal concentrations $\left(\mathrm{LC}_{50}\right.$ and $\left.\mathrm{LC}_{90}\right)$. The ethanol extract was characterized by thin-layer chromatography (TLC) and phytochemical analysis.

Both ethanol and hexane extracts exhibited significant larvicidal activity with $\mathrm{LC}_{50}$ and $\mathrm{LC}_{90}$ of $3.29 \mathrm{mg} / \mathrm{L}$ and $8.13 \mathrm{mg} / \mathrm{L}$; and $7.31 \mathrm{mg} / \mathrm{L}$ and $13.55 \mathrm{mg} / \mathrm{L}$, respectively. The ovicidal activity of the ethanol extract was $8.06 \mathrm{mg} / \mathrm{L}$ and $15.53 \mathrm{mg} / \mathrm{L}$, respectively. Phytochemical screening of the crude ethanol extract of cashew shell wastes indicated the presence of phytochemical constituents such as unsaturated steroids and triterpenoids, free fatty acids, fats and oils, flavonoids, leucoanthocyanins, anthraquinones, and tannins. TLC showed bioactive components of the extract. The larvicidal activity of the ethanol extract decreased slightly after two (2) years with an $\mathrm{LC}_{50}$ of $4.20 \mathrm{mg} / \mathrm{L}$ and $\mathrm{LC}_{90}$ of $9.87 \mathrm{mg} / \mathrm{L}$. The ethanol extracts of $A$. occidentale showed promising potential as an alternative source to control the spread of the dengue and zika vector, $A$. aegypti.
\end{abstract}

\section{Introduction}

Dengue is a severe, often fatal, most rapidly emerging febrile disease transmitted by female Aedes aegypti mosquitoes. In the Philippines, dengue fever and dengue hemorrhagic fever are widespread in all its regions according to World Health Organization. A total of 117, 658 dengue cases and 433 deaths were reported in the year of 2013 [1]. Zika is caused by a virus transmitted primarily also by A. aegypti. This is a mosquito-borne flavivirus that was first identified in Uganda in 1947. Zika virus infection during pregnancy is a cause of congenital brain abnormalities, including microcephaly. Zika virus is a trigger of Guillain-Barre syndrome. There are 57 reported cases of zika from six (6) regions in the country (DOH, 2017). However, there were no reported deaths until this time. These are the reasons behind the efforts of many institution and research bodies to find a solution in controlling the vector of dengue and zika, A. aegypti. Use of chemical control is said to be an effective way used generally by most of the people [2] but these controls have negative drawbacks [3] like insecticide resistance [4], environmental pollution, toxic hazards to human and other non-target organisms [5]. This results in the increasing attention and consideration to natural products [6]. Natural products in various forms have been used for the treatment of pathological conditions [7]. Green larvicides are now being considered because most plants are said to be nontoxic and biodegradable. Unlike the conventional insecticide which is based on single active ingredient, green insecticides comprise of bioactive chemical variations which have behavioral and physiological activities [8]. The researches about the interactions between plants and insects revealed the potential use of plants in fundamental pest control programs [9].

Anacardium occidentale commonly known as "cashew" is a tree in the family Anacardiaceae which produces a seed that is harvested as the cashew nut. The cashew nut is a popular snack and food source. Nigeria was the world's largest producer of cashew nuts with shell in 2010 [10]. The Philippines is actually sixth among the top 10 producers of cashew nuts with shell as of 2010 .

Our main focus is now on the research study of A. occidentale as a potential vector control measure against $A$. aegypti that is cost effective and more importantly, safe for the environment. The use of natural alternatives such as plant extracts can provide the best option as environmentally safe natural larvicides. Therefore, the objectives of the study were to evaluate the larvicidal and ovicidal toxicities of the ethanol and hexane extracts of the shell wastes of $A$. occidentale against $A$. aegypti including its stability and to characterize the ethanol extract by qualitative phytochemical analysis and thin-layer chromatography (TLC).

Correspondence to: Rosalinda C. Torres, Industrial Technology Development Institute, Metro Manila, Philippines, Tel: (632)837-0032; Fax: (632)837-20-71; E-mail: rctorres@itdi.dost.gov.ph; lindactorres@yahoo.com

Key words: Aedes aegypti, Anacardium occidentale, dengue, larvicidal activity, phytochemical analysis, TLC

Received: October 17, 2017; Accepted: October 26, 2017; Published: October 28,2017 


\section{Experimental}

\section{Botanical material}

The cashew shell wastes were collected in Puerto Princesa City, Palawan, Philippines during rainy season in the months of July and August. Specimen label was placed in the plant. Herbarium specimen of the plant collected was prepared and was sent to the National Museum of the Philippines for necessary identification and authentication.

\section{Sample preparation}

The cashew shell wastes were ground with Wiley mill (Thomas Scientific, Model 3379-K05-99). About 300 grams of ground plant material were macerated with $900 \mathrm{~mL}$ of $95 \% \mathrm{EtOH}$ and $\mathrm{n}$-hexane (Chemline Manila, Philippines) for 48 hours. Then, the mixture was filtered with a coarse filter paper. The filtrate was concentrated under vacuum at $55^{\circ} \mathrm{C}$ to a syrupy consistency. This was further evaporated in a water bath at the same temperature to semi-solid extract.

\section{Rearing of Aedes aegypti larvae}

The $3^{\text {rd }}$ and early $4^{\text {th }}$ instars larvae of $A$. aegypti used in the study were reared in the Insectary of the Industrial Technology Development Institute - Department of Science and Technology, Taguig City, Metro Manila, Philippines at $27 \pm 2^{\circ} \mathrm{C}, 80 \pm 5 \%$ humidity and a photoperiod of $12 \mathrm{~h}$ light followed by $12 \mathrm{~h}$ dark (12L: 12D).

\section{Preparation of stock solutions and serial dilutions}

A $1 \%$ or $10,000 \mathrm{mg} / \mathrm{L}$ stock solution was serially diluted in dechlorinated water to different concentrations used in the assay.

\section{Larvicidal Bioassay against $3^{\text {rd }}$ and $4^{\text {th }}$ instars larvae of $A$. aegypti}

The larvicidal bioassay was conducted following the WHO method [11]. The test larvae were exposed to a wide range of test concentrations from 5 to $50 \mathrm{mg} / \mathrm{L}$ and a control to determine the effective dose. After determining the mortality of the larvae in this wide range of concentration, a narrower range from 2 to $25 \mathrm{mg} / \mathrm{L}$ was re-evaluated to determine the lethal concentrations level. The appropriate volume of each extract used in each concentration was added to dechlorinated water to make a $100 \mathrm{~mL}$ volume of solution starting with the lowest concentration. Homogenous batches of twenty $3^{\text {rd }}$ or $4^{\text {th }}$ instars larvae were added by means of droppers to each vessel containing $100 \mathrm{~mL}$ volume of solution concentration under test. Four replicates were set up for each concentration and an equal number of controls were set up simultaneously with dechlorinated water, to which $1 \mathrm{~mL}$ EtOH was added. For negative control, dechlorinated water with $1 \%$ ethanol was used. The test containers were held at $27 \pm 2^{\circ} \mathrm{C}$ and a photoperiod of 12 $\mathrm{h}$ light followed by $12 \mathrm{~h}$ dark (12L: 12D). Each test was run three times on different batches of larvae. The results were recorded where the $\mathrm{LC}_{50}$ and $\mathrm{LC}_{90}$ values and slope and heterogeneity analysis were also noted. Stability of the ethanol extract was determined after two (2) years.

\section{Ovicidal Bioassay against 3rd and 4th instars larvae of $A$. aegypti}

The Aedes aegypti mosquito eggs used in the ovicidal study were reared in the Insectary of Standards and Testing Division, Industrial Technology Development Institute, Department of Science and Technology at a laboratory condition of $27 \pm 2^{\circ} \mathrm{C}$ temperature and 80 $\pm 10 \%$ relative humidity. About 3-5 days old batches of eggs laid in filter papers and dried were used in the test. Batches of 20 eggs were transferred by means of a camel brush to $250 \mathrm{~mL}$ beakers containing $100 \mathrm{~mL}$ volume of solution concentration under test. Four replicates were set up at each concentration with an equal number of controls set up simultaneously. For negative control, dechlorinated tap water with $1 \%$ ethanol was used. The test containers were held at $25-28^{\circ} \mathrm{C}$ and relative humidity of $80 \pm 10 \%$. After 72 hours exposure, the egg emergence was recorded.

\section{Data analysis}

Data from all replicates were pooled for linear regression probit analysis and calculated using SPSS for Windows including 95\% confidence limit. A test series is valid if the relative standard deviation (or coefficient of variation) is less than $25 \%$ or if confidence limits of $\mathrm{LC}_{50}$ overlap (significant level at $P<0.05$ ).

\section{Phytochemical analysis}

The qualitative phytochemical analysis of the extract was performed [12] to detect the presence of secondary metabolites such as alkaloids, tannins, saponins, free fatty acids, unsaturated steroids, triterpenoids, flavonoids, leucoanthocyanins, and anthraquinones.

\section{Thin-layer chromatographic (TLC) fingerprinting/profiling}

Characterization of the A. occidentale extracts was done by thinlayer chromatographic fingerprinting and profiling to determine presence of bioactive compounds. The TLC was carried out in a $20 \mathrm{~cm}$ x $20 \mathrm{~cm}$ pre-coated silica gel $60 \mathrm{~F}_{254}$ TLC plate (Merck, Inc. Darmstadt, Germany) which was cut into squares $(8 \times 11 \mathrm{~cm})$. The solvent systems used were hexane:EtOAc (3:7) and toluene:EtOAc (93:7). The developed chromatogram was visualized by inspecting under ultraviolet light at $254 \mathrm{~nm}$ and $366 \mathrm{~nm}$ and exposing to iodine vapors in a glass jar. The chromatogram was photographed and documented. The Rf values of the spots were then calculated.

\section{Results and discussion}

Both ethanol and hexane extracts exhibited significant larvicidal activity with $\mathrm{LC}_{50}$ and $\mathrm{LC}_{90}$ of $3.29 \mathrm{mg} / \mathrm{L}$ and $8.13 \mathrm{mg} / \mathrm{L}$; and $7.31 \mathrm{mg} / \mathrm{L}$ and $13.55 \mathrm{mg} / \mathrm{L}$, respectively. The ethanol extract also exhibited toxicity against A.aegypti eggs at $\mathrm{LC}_{50}$ of $8.06 \mathrm{mg} / \mathrm{L}$ and $\mathrm{LC}_{90}$ of $15.53 \mathrm{mg} / \mathrm{L}$. The larvicidal activity of the ethanol extract after two (2) years decreased slightly with an $\mathrm{LC}_{50}$ of $4.20 \mathrm{mg} / \mathrm{L}$ and $\mathrm{LC}_{90}$ of $9.87 \mathrm{mg} / \mathrm{L}$. Toxicities exhibited by both ethanol and hexane extracts are comparable to the commercially available biolarvicide, $\mathrm{Ph} \mathrm{Big} \mathrm{R}$ with $\mathrm{LC}_{50}$ and $\mathrm{LC}_{90}$ of $1.71 \mathrm{mg} / \mathrm{L}$ and $8.49 \mathrm{mg} / \mathrm{L}$, respectively.

The extract was reflected to be bioactive since they presented lethal concentrations $\left(\mathrm{LC}_{50}\right.$ and $\left.\mathrm{LC}_{90}\right)$ that are extremely lower than 1000 $\mathrm{mg} / \mathrm{L}$ [13]. The solvent used can contribute to the variation between the fractions since it has been reported that the extraction of active biochemical compounds from plants depends upon the polarity of the solvents used [8]. A number of studies have reported the larvicidal potential of $A$. occidentale supporting the results gathered in the study $[14,15]$.

Phytochemical analysis of the crude ethanol extract of cashew shell waste indicated the presence of free fatty acids, flavonoids, leucoanthocyanins, hydrolyzable tannins, unsaturated steroids and triterpenoids, fats and oils, and anthraquinones (Table 1).

Thin layer chromatographic profiling of the bioactive extracts showed characteristic profile for the plant studied as indicated by the presence of different spots in the chromatogram. These spots represent 
Table 1. Qualitative phytochemical analysis of the ethanol extract of $A$. occidentale shell wastes. + Presence of compounds; - Absence of compounds.

\begin{tabular}{|l|l|l|}
\hline Phytochemical constituent & Qualitative Test & Indication \\
\hline Alkaloids & $\begin{array}{l}\text { Mayer's Test } \\
\text { Dragendorff's Test }\end{array}$ & - \\
\hline Saponins & Froth Test & - \\
\hline Free fatty acids & Sodium carbonate Test & + \\
\hline Leucoanthocyanins & Bate-Smith \& Metcalf Test & + \\
\hline $\begin{array}{l}\text { Flavonoids }(\gamma \text {-benzopyrone } \\
\text { nucleus) }\end{array}$ & Wilstatter “Cyanidin" Test & + \\
\hline Hydrolyzable tannins & Ferric Chloride Test & + \\
\hline $\begin{array}{l}\text { Unsaturated steroid/ } \\
\text { triterpenoids }\end{array}$ & Liebermann-Burchard Test & + \\
\hline Anthraquinones & Borntrager's Test & + \\
\hline Fats and oils & Spot Test & + \\
\hline
\end{tabular}

Table 2. Results of the TLC of the ethanol extract of cashew shell wastes developed in n-hexane: EtOAc (3:7).

\begin{tabular}{|c|c|c|}
\hline Visualizing Agent & Spot Characteristic & hR $\boldsymbol{f}$ values \\
\hline Naked Eye & Purple & 66.67 \\
\hline \multirow{2}{*}{ UV Light $(254 \mathrm{~nm})$} & Purple & 66.67 \\
\cline { 2 - 3 } & Light purple & 75.00 \\
\hline \multirow{2}{*}{ Iodine Crystals } & Orange & 66.67 \\
\cline { 2 - 3 } & Light Orange & 75.00 \\
\hline
\end{tabular}

a measure of the components present in the plant. The chromatogram showed that the extract is UV-active which may indicate the presence of aromatic components and compounds with double bonds that have extended conjugation [16].

Based on literature, more than 2000 plant species are reported to have insecticidal properties [17]. Several studies have reported the potential of $A$. occidentale against $A$. aegypti. A study was conducted on the antioxidant, larvicidal and anti-acetylcholinesterase activities of cashew nut shell liquid constituents namely, cardol, cardanol and anacardic acid. Results of study indicated that these constituents showed good larvicidal activity against A. aegypti [15]. Another study reported that the $A$. aegypti was found to be highly susceptible to cashew nut shell liquid against the immature stages of two mosquitos, A. aegypti and Anopheles subpictus. In addition, sodium anacardate, a bioactive constituent isolated from A. occidentale was found to be nontoxic and reported to have good insecticidal activity [18].

The remarkable toxicity effects exhibited by the ethanol and hexane extracts of $A$. occidentale shell wastes against $A$. aegypti indicate their promising use as natural larvicides for the control of dengue and zika vector. This finding fully supports the results gathered from the present study and suggests that the utilization of $A$. occidentale shell wastes as a new green larvicidal may be considered as a new alternative to combat spreading of dengue and zika virus. Larvicidal products can be developed from the isolated constituents of the A. occidentale shell wastes.

\section{Acknowledgement}

The National Research Council of the Philippines of the Department of Science and Technology, Taguig City, Metro Manila, Philippines is gratefully acknowledged for providing the research grant and the Industrial Technology Development Institute of the Department of Science and Technology for the unwavering support in the continuous implementation of this project. The authors would like to thank also Engr. Elmer T. Ferry and Ms. Librada Fuertes of the Department of Agriculture, Palawan Agricultural Experimental Station for the cashew shell wastes used in this study.

\section{References}

1. Disease surveillance report (2013) National Epidemiology Center. Public Health Surveillance and Informatics Division, Department of Health.

2. Pavela R (2009) Larvicidal effects of some Euro-Asiatic plants against Culex quinquefasciatus Say larvae (Diptera: Culicidae). Parasitology Research 105: 887-892.

3. Pavela R (2008) Larvicidal effects of various Euro-Asiatic plants against Culex quinquefasciatus Say larvae (Diptera: Culicidae). Parasitology Research 102: 555-559.

4. Severini C, Rom R, Marinucci M, Rajmond M (1993) Mechanisms of insecticide resistance in field populations of Culex pipiens from Italy. J Am Mosq Control Assoc 9: 164-168.

5. Forget O (1989) Pesticides, necessary but dangerous poisons. The IDRC Reports 18 : 7-13.

6. Pirali-Kheirabadi K, da Silva JAT (2010) Lavandula angustifolia essential oil as a novel and promising natural candidate for tick (Rhipicephalus (Boophilus) annulatus) control. Experimental Parasitology 126: 184-186.

7. Bombardelli E, Bombardelli V (2006) Twenty years' experience in the botanical health food market. Fitoterapia 76: 495-507.

8. Ghosh A, Chowdhury N, Chandra G (2012) Plant extracts as potential mosquito larvicides. Indian J Med Res 135: 581-598. [Crossref]

9. Kamaraj C, Abdul Rahuman A, Mahapatra A, Bagavan A, Elango G (2010) Insecticida and larvicidal activities of medicinal plant extracts against mosquitoes. Parasitology Research. 107: 1337-1349.

10. Hammed LA, Anikwe JC (2008) Cashew Nuts and Production Development in AmEuras. J Sci Res 3: 54-61.

11. World Health Organization (2005) Instructions for determining the susceptibility or resistance of mosquito larvae to insecticide. WHO.

12. Guevara BQ (2005) A Guidebook and Plant Screening: Phytochemical and Biological. University of Santo Tomas Publishing House, Manila.

13. de Morais SM, Facundo VA, Bertini LM, Cavalcanti ESB, dos Anjos Júnior JF, et al. (2007) Chemical composition and larvicidal activity of essential oils from Piper species. Biochemical Systematics and Ecology 35: 670-675.

14. Lomonaco D, Santiago GMP, Ferreira YS, Arriaga AMC, Mazzetto SE, et al. (2009) Study of technical CNSL and its main components as new green larvicides. Green Chem 11: 31-33.

15. Oliveira MCS, de Morais SM, Magalhaes DV, Batista WP, Vieira IGP, et al. (2011) Antioxidant, larvicidal and antiacetylcholinesterase activities of cashew nut shell liquid constituents. Acta Trop 117: 165-170.

16. Pavia DL, Lampman GM, Kriz GS, Vyvyan JR (2009) Introduction to Spectroscopy (4th Edn) Brooks/Cole, California, USA.

17. Mangalat S, Narayanan V (2004) Herbal larvicides to control mosquito larvae. Nat Prod Radiance 3: 24-26.

18. Farias DF, Cavalheiro MG, Viana SM, De Lima GP, da Rocha-Bezerra LC, et al (2009) Insecticidal action of sodium anacardate from Brazilian cashew nut shell liquid against Aedes aegypti. J Am Mosq Control Assoc 25: 386-389. [Crossref]

Copyright: (C2017 Torres RC. This is an open-access article distributed under the terms of the Creative Commons Attribution License, which permits unrestricted use, distribution, and reproduction in any medium, provided the original author and source are credited. 